\title{
POTENSI PENGEMBANGAN EKOWISATA MANGROVE DI KAMPUNG TANJUNG BATU, KECAMATAN PULAU DERAWAN, KABUPATEN BERAU \\ (Potential Development of Mangrove Ecotourism in Tanjung Batu Village, Derawan Island District, Berau Regency)
}

\author{
Mukhlisi* \\ Balai Litbang Teknologi Konservasi Sumber Daya Alam (Balitek KSDA) Samboja \\ Jl. Soekarno Hatta Km 38 Samboja Po Box 578 Balikpapan 76112.
}

*Tel: 081273953693. Email: mukhlisi@ forda-mof.org.

Diterima: 11 November 2016

Disetujui: 5 Januari 2017

\begin{abstract}
Abstrak
Jasa lingkungan berupa ekowisata pada kawasan hutan mangrove di Tanjung Batu, Kabupaten Berau, Provinsi Kalimantan Timur merupakan salah satu potensi sumber daya alam yang belum banyak dimanfaatkan. Penelitian ini bertujuan untuk menganalisis potensi pengembangan ekowisata mangrove di Kampung Tanjung Batu berdasarkan penilaian kondisi obyek daya tarik wisata alam, persepsi wisatawan dan masyarakat, serta potensi nilai ekonomi yang dimiliki. Metode penelitian yang digunakan melalui observasi, wawancara terstruktur, dan studi pustaka. Analisis data obyek daya tarik wisata alam dilakukan melalui skoring dan pembobotan, persepsi wisatawan dan masyarakat dilakukan secara deskriptif, sedangkan potensi nilai ekonomi berdasarkan pada nilai kesediaan membayar (Willingness to Pay/WTP). Hasil penelitian menunjukkan bahwa kawasan hutan mangrove Tanjung Batu prospektif untuk dikembangkan sebagai destinasi ekowisata dengan skor total daya tarik wisata alam berada pada kategori tinggi. Persepsi wisatawan dan masyarakat sekitar mendukung penuh upaya pengembangan ekowisata dengan potensi nilai ekonomi diperkirakan sebesar Rp. 1.423.914.894 tiap tahun.
\end{abstract}

Kata kunci: ekowisata, jasa lingkungan, Kepulauan Derawan, mangrove, pesisir.

\begin{abstract}
Environmental services in the form ecotourism at mangrove forest of Tanjung Batu, Berau District, East Kalimantan Province is one of the natural resources that have not been used. The aim of this study was to analyze the potential of ecotourism development in mangrove forest of Kampung Tanjung Batu which is based on rating natural tourist attraction object, the perception of tourists and local community, as well as potential economic value. Data were collected through observation, interviews, and study of related literature. Natural tourist attraction object analysis was conducted by the scoring, whereas the perception of tourists and local community by descriptive method, and economic value based on willingness to pay. The result of study showed that mangrove forest area of Tanjung Batu prospective to be developed as an ecotourism destination with a total score of natural attractions that were in the high category. The perception of tourists and the local community fully supports the efforts of ecotourism development with potential economic value was estimated at Rp. 1.423.914.894 per annum.
\end{abstract}

Keywords: ecotourism, environmental services, coastal, Derawan archipelago, mangrove

\section{PENDAHULUAN}

Pengembangan ekowisata mangrove merupakan salah satu upaya pemanfaatan jasa lingkungan dari kawasan pesisir secara berkelanjutan. Ekowisata pada hutan mangrove dipandang dapat bersinergi dengan langkah konservasi ekosistem hutan secara nyata (Mulyadi dan Fitriani, 2012). Meskipun demikian, dalam prakteknya pengembangan ekowisata pada hutan mangrove harus tetap dikelola dengan menghindari resiko dan dampak negatif terhadap lingkungan, seperti dengan memperhatikan aspek kesesuaian serta daya dukung lingkungannya (Muhammad dkk, 2012; Kusaeri dkk, 2015).

Hutan mangrove Tanjung Batu adalah bagian dari sebaran alami hutan mangrove di pesisir Kabupaten Berau. Secara geografis kawasan tersebut terletak pada lokasi sangat strategis, berada pada daratan utama Kalimantan yang menjadi pintu gerbang/transit point bagi para wisatawan yang ingin menuju obyek wisata bahari yang telah terkenal di Kepulauan Derawan, seperti Pulau Derawan, Pulau Kakaban, Pulau Sangalaki, Pulau Semama, dan Pulau Maratua. Kawasan tersebut juga berada di antara coral triangle (segi tiga) pertemuan terumbu karang terbaik dunia yang 
diketahui sebagai salah satu pusat megabiodiversitas sumber daya laut (Wiryawan, 2008).

Potensi jasa lingkungan hutan mangrove sebagai destinasi ekowisata sampai saat ini belum di optimalkan sebagai alternatif pengelolaan hutan yang lebih ramah lingkungan, khususnya di kawasan Tanjung Batu. Padahal, dalam rencana pengelolaan Taman Pesisir Kepulauan Derawan (TKPD), hutan mangrove pesisir Tanjung Batu berbatasan langsung dengan zona yang diperuntukan untuk pariwisata dan konservasi. Pengembangan ekowisata secara terpadu dengan destinasi yang beragam di sekitarnya dapat meningkatkan jalur wisata secara optimal (Razak dan Suprihardjo, 2013) dan secara bersamaan juga akan memberikan dampak positif terhadap pertumbuhan ekonomi regional.

Studi terkait peluang pengembangan dan kesesuaian ekosistem mangrove sebagai destinasi ekowisata telah banyak dilakukan di berbagai tempat, seperti di Taman Nasional Togean (Laapo dkk, 2010), Pulau Pramuka (Putra dkk, 2015) dan Deli Serdang (Khoiri dkk, 2014), namun studi serupa masih minim dilakukan pada area hutan mangrove di Kepulauan Derawan, khususnya Tanjung Batu. Beberapa studi terdahulu telah dilakukan untuk pengembangan ekowisata mangrove Tanjung Batu, di antaranya inventarisasi keragaman jenis pohon mangrove dan juga burung sebagai Obyek Daya Tarik Wisata Alam (ODTWA) (Mukhlisi, 2013; Mukhlisi dan Sidiyasa, 2014). Berkaitan dengan hal tersebut, maka untuk mengetahui secara lebih mendalam potensi usaha pengembangan ekowisata hutan mangrove di Tanjung Batu perlu dilakukan studi lebih lanjut.

Penelitian ini bertujuan untuk menganalisis potensi pengembangan ekowisata mangrove di Tanjung Batu ditinjau dari aspek ODTWA, persepsi wisatawan dan masyarakat sekitar, serta potensi nilai ekonomi yang dimiliki. Diharapkan hasil penelitian ini dapat menjadi salah satu acuan bagi para para pihak terkait dalam hal menentukan kebijakan pengelolaan jasa lingkungan hutan mangrove dan sektor kepariwisataan secara berkelanjutan, khususnya di Kepuluan Derawan.

\section{METODE PENELITIAN}

\section{Waktu dan Lokasi}

Penelitian dilaksanakan di Kampung Tanjung Batu dan Kampung Pulau Derawan. Secara administrasi pemerintahan, kedua kampung tersebut berada di Kecamatan Pulau Derawan, Kabupaten Berau, Provinsi Kalimantan Timur. Pengumpulan data penelitian ini telah dilaksanakan pada bulan Juni dan Agustus tahun 2011.

\section{Prosedur}

Pengumpulan data dilakukan melalui observasi lapangan secara langsung untuk menilai skor dari potensi ODTWA yang dimiliki. Wawancara terstruktur dilakukan terhadap para wisatawan dan masyarakat sekitar Tanjung Batu. Pemilihan sampel responden wisatawan berdasar pendekatan accidental sampling, yaitu hanya melakukan wawancara terhadap responden yang kebetulan ditemui dan bersedia untuk diwawancarai yang berada di Tanjung Batu dan sekitar Kepulauan Derawan. Sementara itu, wawancara terhadap responden masyarakat dengan pendekatan teknik quota sampling (dijatah) berdasarkan kelompok pekerjaannya, yaitu nelayan dan non nelayan masing-masing sebanyak 25 orang.

\section{Analisis Data}

Analisis data untuk penilaian potensi pengembangan ekowisata mangrove di Tanjung Batu berdasarkan pembobotan dan penilaian dengan menggunakan modifikasi tabel kriteria dan indikator pedoman analisis ODTWA yang ditetapkan oleh Direktorat Wisata Alam dan Pemanfaatan Jasa Lingkungan, Dirjen Perlindungan Hutan dan Konservasi Alam, Departemen Kehutanan (Anonim, 2003). Hasil pembobotan dan penilaian kemudian dihitung nilai indeks potensi pengembangan ekowisata dengan 3 kategori utama yaitu tinggi (nilai potensi $\geq 80 \%$ ), sedang (nilai potensi $51-79 \%$ ) dan rendah (nilai potensi $\leq 50 \%$ ).

Hasil wawancara terhadap wisatawan dan masyarakat sekitar dianalisis secara deskriptif. Selanjutnya, potensi total nilai ekonomi pengembangan ekowisata dihitung berdasar nilai kesediaan membayar (Willingness to Pay/WTP) wisatawan dengan rumus Hasiani dkk (2009).

$$
\text { TWTP }=\sum_{n=i}^{n} \text { WTPi }\left(\frac{\mathrm{n}}{\mathrm{N}}\right) \mathrm{P}
$$

di mana:

TWTP : Total WTP

WTPi : WTP individu sampel ke-i

ni : Jumlah sampel ke-i yang bersedia membayar sebesar WTP

$N \quad$ : Jumlah sampel

$P \quad:$ Jumlah populasi

I : Responden ke-i yang bersedia membayar $(\mathrm{i}=1,2, \ldots, \mathrm{n})$

\section{HASIL DAN PEMBAHASAN}

\section{Penilaian Potensi ODTWA Hutan Mangrove Tanjung Batu}

Tanjung Batu merupakan daerah penyangga bagi kawasan wisata di sekitar Kepulauan Derawan 
yang menjadi tujuan wisata bertaraf internasional. Kecenderungan wisatawan untuk menikmati keindahan dan keunikan wisata bahari dapat menjadi paket pelengkap untuk menarik minat wisatawan singgah ke kawasan hutan mangrove di Tanjung Batu. Karakteristik pantai di sekitar ekosistem mangrove Tanjung Batu cukup unik dan indah karena bersambungan langsung dengan ekosistem terumbu karang di mana tekstur tanahnya dominan cenderung berpasir. Hasil penilaian terhadap potensi ODTWA ditampilkan pada Tabel 1.

Berdasar Tabel 1 terlihat bahwa untuk kriteria daya tarik obyek wisata memiliki indeks nilai $88,10 \%$ atau berada pada kategori tinggi. Kondisi ini mengindikasikan jika pengembangan ekowisata pada kawasan hutan mangrove di Tanjung Batu memiliki prospek baik jika dilakukan secara serius. Potensi ODTWA utama dari hutan mangrove Tanjung Batu terutama meliputi kekayaan biota perairan, serta satwa liar dan vegetasi mangrove yang menempati habitat di dalamnya. Secara alami, Tanjung Batu sebagai bagian dari pesisir Berau dan gugusan pulau-pulau sekitarnya dikenal sebagai jantungnya coral triangle (segi tiga) pertemuan terumbu karang terbaik di dunia yang memiliki luas sekitar 5,7 juta ha meliputi perairan laut Indonesia, Malaysia, Papua Nugini, Filipina, Timor Leste, dan Kepulauan Solomon (Wiryawan, 2008). Hutan mangrove Tanjung Batu berbatasan langsung dengan zona perlindungan ekosistem terumbu karang pada Taman Pesisir Kepulauan Derawan (TKPD).

Potensi ODTWA berupa keragaman jenis mangrove di Tanjung Batu seperti dilaporkan oleh Mukhlisi dan Sidiyasa (2014) terdiri dari 21 jenis mangrove yang tersusun atas 20 marga dan 50 suku. Tujuh jenis di antaranya adalah kelompok mangrove mayor, lima jenis mangrove minor, dan sembilan jenis asosiasi mangrove. Lima jenis pohon mangrove paling dominan ditemukan meliputi jenis Camptostemon philippinense, Sonneratia alba, Rhizophora apiculata, Xylocarpus granatum, dan Lumnitzera littorea.

Keunikan dan kekhasan yang dapat ditonjolkan dari vegetasi mangrove adalah ditemukannya jenis mangrove yang telah masuk kategori langka dan terancam punah, yaitu C. philippinense. IUCN (The International Union for Conservation of Nature and Resources) telah memasukkannya ke dalam red list (daftar merah) dengan status endangered (terancam punah) sejak tahun 2004. Meskipun demikian, jenis tersebut justru masih dapat ditemukan secara melimpah di sekitar pesisir Tanjung Batu dan mendominasi pada berbagai strata pertumbuhan vegetasi mangrove.

Potensi ODTWA berupa kehadiran satwa yang dapat menjadi atraksi menarik di antaranya adalah berupa jenis-jenis burung, reptil biawak (Varanus salvator), dan primata terutama monyet ekor panjang (Macaca fascicularis) dan primata endemik Kalimantan, yaitu bekantan (Nasalis

Tabel 1. Hasil penilaian potensi obyek daya tarik wisata alam di Tanjung Batu.

\begin{tabular}{|c|c|c|c|c|c|c|c|}
\hline Potensi & Kriteria & $\begin{array}{l}\text { Bobot } \\
\text { (a) }\end{array}$ & $\begin{array}{l}\text { Nilai } \\
\text { (b) }\end{array}$ & $\begin{array}{c}\text { Nilai } \\
\text { potensi } \\
(\mathrm{a} \times \mathrm{x})\end{array}$ & $\begin{array}{l}\text { Total nilai } \\
\text { ODTWA }\end{array}$ & $\begin{array}{c}\text { Indeks } \\
\text { nilai }(\%)\end{array}$ & Klasifikasi \\
\hline $\begin{array}{l}\text { Daya tarik } \\
\text { SDA }\end{array}$ & Daya tarik obyek wisata & 6 & 185 & 1110 & 1260 & 88,10 & Tinggi \\
\hline \multirow{13}{*}{$\begin{array}{l}\text { Unsur } \\
\text { penunjang }\end{array}$} & $\begin{array}{l}\text { Potensi pasar } \\
\text { Kadar } \\
\text { hubungan/aksesbilitas }\end{array}$ & $\begin{array}{l}5 \\
5\end{array}$ & $\begin{array}{l}61 \\
60\end{array}$ & $\begin{array}{l}305 \\
300\end{array}$ & $\begin{array}{l}330 \\
900\end{array}$ & $\begin{array}{l}92,42 \\
33,33\end{array}$ & $\begin{array}{l}\text { Tinggi } \\
\text { Rendah }\end{array}$ \\
\hline & Kondisi sekitar kawasan & 5 & 150 & 750 & 1200 & 62,50 & Sedang \\
\hline & Pengelolaan dan pelayanan & 4 & 65 & 260 & 360 & 72,22 & Sedang \\
\hline & Iklim & 4 & 75 & 300 & 480 & 62,50 & Sedang \\
\hline & Akomodasi & 3 & 30 & 90 & 90 & 100,00 & Tinggi \\
\hline & $\begin{array}{l}\text { Sarana dan prasarana } \\
\text { penunjang }\end{array}$ & 3 & 55 & 165 & 180 & 91,67 & Tinggi \\
\hline & Ketersediaan air bersih & 6 & 125 & 750 & 900 & 83,33 & Tinggi \\
\hline & $\begin{array}{l}\text { Hubungan dengan obyek } \\
\text { wisata sekitarnya }\end{array}$ & 1 & 100 & 100 & 100 & 100,00 & Tinggi \\
\hline & Keamanan & 5 & 85 & 425 & 600 & 70,83 & Tinggi \\
\hline & Daya dukung kawasan & 3 & 130 & 390 & 450 & 86,67 & Tinggi \\
\hline & Pengaturan pengunjung & 3 & 10 & 30 & 90 & 33,33 & Rendah \\
\hline & Pemasaran & 4 & 5 & 20 & 120 & 16,67 & Rendah \\
\hline & Pangsa pasar & 3 & 75 & 225 & 270 & 83,33 & Tinggi \\
\hline
\end{tabular}

Sumber: Analisis data primer (2011). 
larvatus). Keragaman satwa burung berdasarkan identifikasi Mukhlisi (2013) telah mendaftarkan 31 jenis burung yang hidup di sekitar hutan mangrove Tanjung Batu. Enam jenis burung yang ditemukan di antaranya termasuk kategori jenis burung yang dilindungi yaitu elang bondol (Haliastur indus), elang laut perut putih (Haliaeetus leucogaster), kuntul perak (Egretta intermedia), kipasan belang (Rhipidura javanica), gajahan pengala (Numenius phaopus), dan burung madu bakau (Nectarinia calcostheta). Selain itu, di lokasi ini juga dapat ditemukan tujuh jenis burung migran, yaitu kokokan laut (Butorides striatus), cekakak suci (Halycon sancta), Numenius phaopus, layanglayang pasir (Riparia riparia), trinil kaki merah (Tringa totanus), trinil semak (Tringa glareola), dan trulek kelabu (Vanellus cinereus).

Bila dibandingkan dengan penilaian kesesuaian pengembangan ekowisata pada beberapa kawasan hutan mangrove lain di Indonesia, seperti di Taman Nasional Togean (Laapo, dkk, 2010), Pulau Pramuka (Putra, dkk, 2015) dan di Deli Serdang (Khoiri, dkk, 2014) umumnya juga mendapatkan kategori sesuai/layak. Meskipun demikian, ditinjau dari aspek keunikan dan kekhasan flora dan fauna sebagai ODTWA maka hutan mangrove Tanjung Batu memiliki beberapa kelebihan, di antaranya yaitu komposisi jenis mangrove yang lebih beragam, ditemukannya satu jenis mangrove langka (C. philippinense), serta terdapat primata endemik bekantan atau monyet belanda ( $N$. larvatus) yang hanya hidup di Pulau Kalimantan.

Selain potensi flora dan fauna yang dimiliki, potensi daya tarik lainnya dari kekayaan seni budaya masyarakat sekitar. Penduduk kampung Tanjung Batu yang menetap di sekitar hutan mangrove mempunyai kekayaan seni dan budaya yang masih dipegang teguh hingga saat ini. Sebagian besar penduduk Tanjung Batu didominasi oleh etnis Bajau dan Bugis yang memiliki kultur sangat kuat dengan kehidupan pesisir dan laut. Sebagai ucapan rasa syukur kepada Tuhan atas hasil tangkapan para nelayan di laut, setiap tahunnya masyarakat etnis Bajau di Tanjung Batu mengadakan upacara berupa pesta adat (pesta laut) yang bernama Dalling. Pesta adat tersebut diisi dengan berbagai ritual, nyayian, dan tari-tarian khas masyarakat pesisir Bajau.

Kriteria kadar hubungan/aksesbilitas, pengaturan pengunjung, serta pemasaran memiliki indeks nilai yang tergolong rendah. Kondisi jarak antara Tanjung Batu dari ibukota Kabupaten Berau (Tanjung Redeb) adalah sekitar $110 \mathrm{~km}$ dengan waktu tempuh 2,5-3 jam, sedangkan perjalanan darat dari ibu kota provinsi (Samarinda) membutuhkan waktu tempuh hingga 13 jam dengan kondisi jalan yang belum sepenuhnya baik. Sebagian besar wisatawan baik lokal dan domestik berasal dari luar kabupaten/provinsi justru menggunakan akses perjalanan udara. Selain itu, di kampung Tanjung Batu juga terdapat dermaga pelabuhan untuk menunjang kegiatan transportasi lewat jalur laut yang menghubungkan dengan pulau-pulau tujuan wisata serta terkoneksi dengan jalur pelayaran dari Pulau Tarakan di Kalimantan Utara.

Indeks nilai pengaturan pengunjung dan pemasaran yang rendah dapat disebabkan karena lokasi hutan mangrove di Tanjung Batu belum diresmikan sebagai salah satu destinasi wisata. Secara kelembagaan belum ada institusi yang berwenang untuk melakukan pengelolaan hutan mangrove di Tanjung Batu sebagai ODTWA, sehingga belum ada pengaturan pengunjung dan strategi pemasaran yang dijalankan. Berdasarkan perencanaan, wilayah tersebut akan dikembangkan sebagai Pusat Informasi Mangrove (PIM) Berau dengan tujuan untuk konservasi ekosistem mangrove. Selanjutnya, ditinjau dari hubungan dengan obyek wisata di sekitarnya maka hutan mangrove Tanjung Batu memiliki keunggulan karena terkoneksi dan menjadi jalur transit bagi para wisatawan yang ingin beriwsata bahari kepulauan Derawan yang telah lama terkenal hingga ke manca negara. Hubungan dengan ODTWA di sekitarnya ditampilkan pada Gambar 1.

Merujuk pada Gambar 1 dapat dipahami jika lokasi Tanjung Batu menjadi transit bagi para wisatawan untuk menuju lokasi wisata bahari di pesisir Berau, sehingga memiliki hubungan yang kuat dengan obyek wisata di sekitarnya. Keuntungan ini sekaligus dapat menjadikannya dalam pengelolaan pariwisata secara terpadu. Kabupaten Berau secara keseluruhan memiliki 41 pulau, beberapa di antaranya menjadi destinasi wisata terkenal yang kerap disebut kawasan wisata Kepulauan Derawani yaitu sebagai berikut:

a. Pulau Derawan: Pulau ini berukuran kecil namun telah terkenal sebagai salah satu destinasi untuk berlibur dengan kondisi terumbu karang yang menarik untuk menyelam dan bermain di pantai, serta menjadi salah satu tempat bertelur penyu hijau. Terdapat fasilitas penginapan yang lengkap dengan harga yang bervariasi. Waktu tempuh antara Tanjung Batu menuju P. Derawan sekitar 45 menit dengan menggunakan jasa angkutan speed boat. 


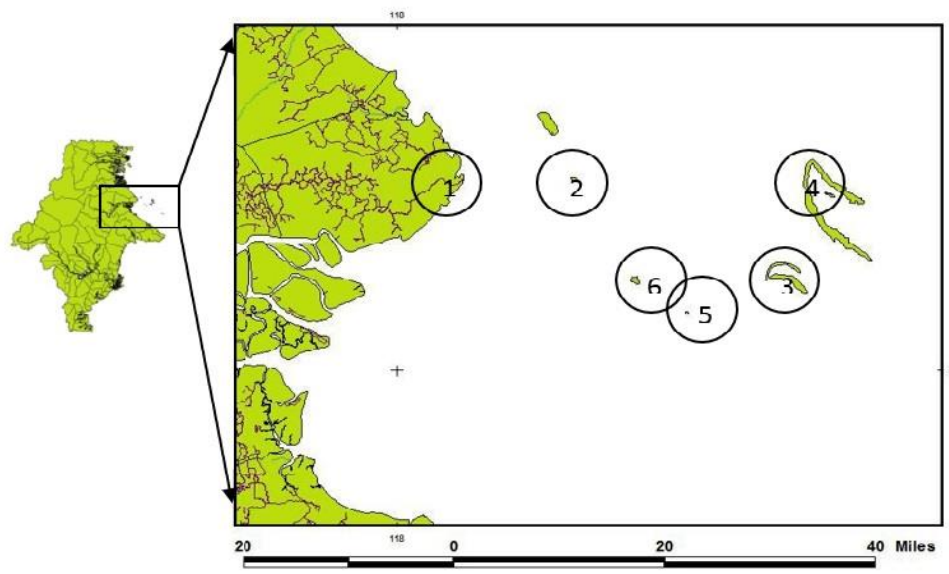

Keterangan:

1. Tanjung Batı

2. P. Derawan

3. P. Kakaban

4. P. Maratua

5. P. Sangalaki

6. P. Semama

Gambar 1. Peta situasi dan obyek wisata di sekitar Tanjung Batu.

b. Pulau Sangalaki dan Semama: Kedua pulau tersebut merupakan kawasan konservasi berupa Taman Wisata Laut dan Suaka Margasatwa. Menjadi habitat utama bertelur terutama bagi penyu hijau. Pulau ini dikelola oleh Balai Konservasi Sumber Daya Alam (BKSDA) Kalimantan Timur. Wisatawan dapat berkunjung untuk mengamati keindahan panorama pulau, menyelam, dan mengamati aktivitas bertelur penyu.

c. Pulau Kakaban: Pulau ini memiliki keunikan karena di bagian tengah pulau terdapat danau air payau dan menjadi habitat penting bagi empat jenis ubur-ubur yang telah berevolusi sehingga tidak memiliki penyengat. Danau air payau seperti ini hanya ada dua di dunia, yaitu di Kakaban dan di Palau, Micronesia. Keberadaan ubur-ubur tersebut menjadi salah satu daya tarik utama penyelaman bagi wisatawan di Pulau Kakaban.

d. Pulau Maratua: Pulau ini merupakan pulau terbesar dengan ukuran 2376 ha dan berjarak $50 \mathrm{Km}$ dari Tanjung Batu atau pesisir daratan Kalimantan dengan endemisitas fauna cukup tinggi (Chua dkk, 2015). Pulau ini memiliki sumber air tawar sehingga terdapat permukiman dan resort dengan keindahan pantai dan lokasi untuk berenang untuk pengamatan ikan terutama manta ray, paus, dan juga lumba-lumba (Mellawati dkk, 2010).

Sebagai pusat administrasi pemerintahan bagi Kecamatan Pulau Derawan, Tanjung Batu terletak di daratan pulau Kalimantan dan telah memiliki berbagai fasilitas umum, seperti pasar, bank, termasuk penginapan bagi para tamu dan wisatawan, sehingga hal ini turut mempengaruhi indeks nilai akomodasi yang sangat tinggi hingga mencapai $100 \%$. Pada radius $<15 \mathrm{~km}$ terdapat banyak penginapan atau cottage yang disediakan untuk para wisatawan. Saat ini telah berdiri setidaknya empat buah penginapan. Di antara penginapan tersebut bahkan ada yang sudah berdiri di dekat kawasan hutan mangrove Tanjung Batu dengan mengusung konsep penginapan di atas air laut agar mempermudah para pengunjung menikmati pemandangan ekosistem mangrove sekaligus laut lepas.

Infrastruktur pendukung secara langsung yang telah dibangun di kawasan hutan mangrove sampai saat ini belum dimiliki. Kondisi ini menyebabkan bagi wisatawan yang ingin menjelajah hutan mangrove tidak dapat dilakukan dengan berjalan kaki melalui papan trekking yang umum tersedia di kawasan ekowisata mangrove. Observasi wisatawan baru dapat dilakukan dengan menggunakan perahu atau berjalan kaki di sekitar hutan mangrove. Dalam perencanaan pariwisata dan pengelolaan hutan mangrove di Kabupaten Berau, saat ini tengah diinisiasi konsep pembangunan PIM Berau yang terletak di Desa Tanjung Batu (Mukhlisi dan Sidiyasa, 2014). Konsep ini akan mengintegrasikan aspek ekowisata dan pengelolaan hutan mangrove secara berkelanjutan dengan berbagai fasilitas pendukung.

Potensi pasar dari pengembangan ODTWA hutan mangrove di Tanjung Batu tergolong tinggi dengan ditunjukkan nilai indeks 92,42\%. Kunjungan wisatawan berasal baik dari wilayah Kalimantan Timur maupun luar provinsi bahkan wisatwan mancanegara. Jumlah wisatawan ke Berau tahun 2015 mencapai hampir 100 ribu dengan rincian 94 ribu adalah wisatawan nusantara dan 5 ribu di antaranya adalah wisatawan asing, diperkirakan sampai dengan akhir 2016 jumlah kunjungan wisatawan akan terus naik sebanyak 10\% (Anonim, 2016). Potensi peningkatan jumlah pengunjung dalam jumlah besar tersebut memberikan keuntungan dari segi ekonomi, namun harus tetap memperhatikan daya dukung fisik kawasan hutan mangrove itu sendiri. Yuniarsih, dkk (2013) menyebutkan strategi pengembangan ekowisata dapat dilakukan dengan simulasi jangka 
panjang terhadap daya dukung fisik, sehingga dalam kondisi tertentu dapat dilakukan pembatasan jumlah dan jam kunjungan agar kondisi ekosistem hutan tetap terjaga.

\section{Persepsi Wisatawan dan Masyarakat Sekitar}

Hasil analisis persepsi terhadap wisatawan dan masyarakat dibagi menjadi dua bagian yaitu, persepsi untuk wisatawan serta untuk masyarakat sekitar Tanjung Batu. Pada Gambar 2 ditampilkan hasil analisis persepsi wisatawan dan masyarakat sekitar terhadap rencana pengembangan ekowisata mangrove di Tanjung Batu.

Berdasarkan Gambar 2 terlihat jika sebagian besar wisatawan dan masyarakat sekitar menyatakan setuju terhadap upaya pengembangan ekowisata mangrove. Kondisi ini menunjukkan bahwa ada dukungan penuh dari para pihak terhadap upaya pengembangan ekowisata mangrove tersebut, tinggal bagaimana dukungan tersebut dapat berimplikasi terhadap minat dan jumlah kunjungan wisatawan ke depannya. Alasan para wisatawan umumnya adalah karena posisi yang berdekatan dengan kawasan wisata sekitarnya, sehingga relatif lebih mudah untuk dijangkau atau dikunjungi. Selain itu, persepsi positif dari masyarakat sekitar juga dapat dioptimalkan dalam bentuk pengembangan ekowisata berbasis masyarakat yang sangat membutuhkan kesepahaman dan koordinasi antar pihak. Bentuk pengembangan ini lebih berkelanjutan dan selaras dengan triple track strategy yaitu pro-poor (pengentasan kemiskinan), pro-growth (partumbuhan), pro-job (penyerapan tenaga kerja) dan proenvirontment (melestarikan lingkungan) (Salim dan Purbani, 2015).

Pengembangan ekowisata mangrove diharapkan dapat meningkatkan perekonomian

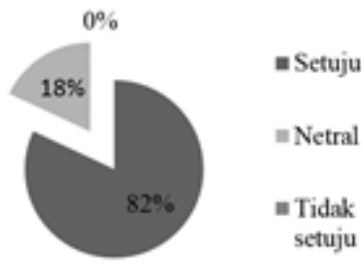

(a) masyarakat sekitar melalui berbagai jenis usaha seperti penginapan, perdagangan, maupun jasa lainnya. Bagi sebagian masyarakat Tanjung Batu selama ini kegiatan wisata di sekitar kepulauan Derawan mampu menggerakkan roda ekonomi terutama melalui jasa penyebrangan dari dermaga Tanjung Batu ke pulau Derawan dan wilayah sekitarnya. Razak dan Suprihardjo (2013) menguraikan untuk meningkatkan nilai ekonomi secara keseluruhan pada kawasan yang memiliki keragaman obyek wisata bahari berdekatan diperlukan konsep zonasi obyek wisata secara terpadu dan saling terhubung satu sama lain. Selanjutnya, Beljai dkk (2014) menjelaskan dengan mempertimbangkan intensitas penggunaan ruang, maka penataan lanskap wisata alam dapat dibagi menjadi tiga zonasi utama yaitu zona intensif, semi intensif, dan ekstensif.

Selanjutnya hasil analisis persepsi wisatawan terhadap kemungkinan untuk melakukan kunjungan dan pengetahuan masyarakat tentang pelestarian hutan mangrove ditampilkan pada Gambar 3.

Respon positif wisatawan terhadap kemungkinan kunjungan dengan $78 \%$ responden menyatakan bersedia mengindikasikan potensi pasar yang dimiliki. Kawasan wisata di sekitar Kepulauan Derawan merupakan destinasi yang mengandalkan keindahan alam laut, sehingga menjadi tempat favorit untuk berwisata. Perbedaan produk wisata yang ditawarkan yaitu keunikan hutan mangrove dapat menjadi ciri pembeda yang menarik sekaligus menjadi pelengkap destinasi wisata sekitarnya yang berorientasi pada wisata bahari. Sebagai contoh, produk wisata dari Mangrove Information Center (MIC) Bali yang telah dikembangkan seperti pendidikan lingkungan dan lintas alam di sekitar mangrove (mangrove eductional tour and trekking), pengamatan burung

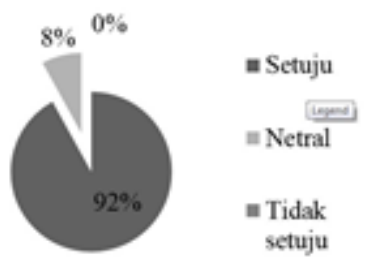

(b)

Gambar 2. Persepsi (a) wisatawan dan (b) masyarakat terhadap aspek rencana pengembangan ekowisata.

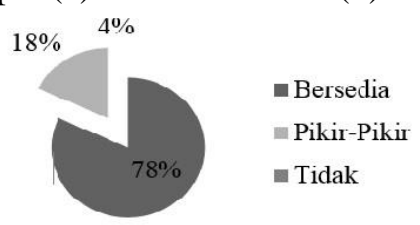

Gambar 3. Persepsi terhadap (a) kemungkinan kunjungan wisatawan dan (b) pengetahuan masyarakat

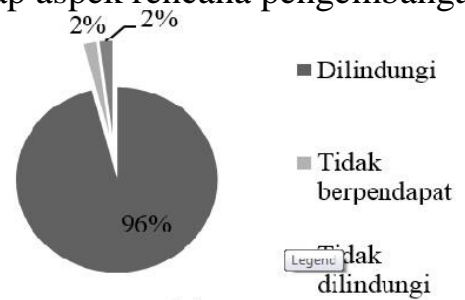

Gambar 3. Persepsi terhadap (a) kemungkinan kunjungan wisatawan dan (b) pengetahuan masyarakat Tanjung Batu tentang pelestarian hutan mangrove. 
Tabel 2. Nilai kesediaan membayar pengunjung.

\begin{tabular}{lccc}
\hline No & Nilai kesediaan membayar (Rp) & Jumlah responden (orang) & Persentase $(\%)$ \\
\hline 1 & $0-5.000$ & 20 & 40 \\
2 & $5.001-10.000$ & 15 & 30 \\
3 & $10.001-15.000$ & 0 & 0 \\
4 & $15.001-20.000$ & 3 & 6 \\
5 & $\geq 20.001$ & 12 & 24 \\
& Total & 50 & 100 \\
\hline
\end{tabular}

Sumber: Analisis data primer (2011).

(bird watching), bermain kano (canoeing), berlayar menggunakan perahu (boating), maupun pengadopsian pohon mangrove (mangrove tree adoption) (Sudiarta, 2009). Oleh karena itu, persepsi wisatawan terhadap destinasi ekowisata mangrove dapat didukung dengan penguatan brand identity dan brand image serta strategi pemasaran yang berorientasi pada segmentation, targeting, dan positioning.

Berdasarkan Gambar 3 terlihat pengetahuan masyarakat tentang keberadaan hutan mangrove dilindungi sangat tinggi. Umumnya responden mengetahui lewat sosialisasi dan penyuluhan yang dilakukan oleh pemerintah atau organisasi kemasyarakatan tentang perlindungan dan larangan penebangan pohon mangrove. Hal ini berkaitan erat juga dengan keberadaan Taman Pesisir Kepulauan Derawan (TPKD) yang telah ditetapkan oleh Bupati Berau melalui Peraturan Bupati Berau No. 516 Tahun 2013. Bahkan, saat ini terdapat organisasi kemasyarakatan JALA (Jaringan Nelayan) di Kampung Tanjung Batu yang sangat peduli terhadap pelestarian terumbu karang dan ekosistem mangrove, khususnya di sekitar perairan Tanjung Batu.

\section{Potensi Ekonomi dari Nilai Kesediaan Membayar Pengunjung}

Nilai kesediaan membayar merupakan nilai moneter yang bersedia diberikan seseorang terhadap barang dan jasa yang dihasilkan oleh sumber daya alam dan lingkungan. Dalam konteks ini adalah besarnya nilai kesediaan pengunjung untuk dapat menikmati jasa lingkungan ekowisata mangrove di Tanjung Batu. Nilai kesediaan membayar kerap digunakan sebagai salah satu referensi untuk menentukan harga tiket masuk suatu kawasan ekowisata sekaligus menghitung potensi ekonomi yang dimiliki. Nilai kesediaan membayar pengunjung untuk dapat menikmati jasa ekowisata mangrove Tanjung Batu ditampilkan pada Tabel 2.

Berdasarkan hasil rekapitulasi data didapatkan bahwa sebagian besar responden sebanyak 70\% memberikan nilai kesediaan membayar $\leq \mathrm{Rp}$. 10.000 untuk dapat menikmati kunjungan ekowisata mangrove di Tanjung Batu. Berbagai faktor dapat saja berpengaruh terhadap nilai kesediaan pengunjung pada sebuah kawasan obyek ekowisata baik dari faktor internal eksternal pengunjung. Sebagai contoh, Hasiani, dkk (2009) melaporkan jika faktor internal dari pengunjung berupa tingkat pendapatan dan pengetahuan memberikan pengaruh signifikan terhadap besarnya nilai kesediaan membayar pengunjung di Taman Alun Kapuas Pontianak. Menariknya, dalam penelitian ini ditemukan satu orang responden yang menolak untuk memberikan nilai kesediaan membayar karena beranggapan bahwa hutan mangrove adalah milik publik sehingga tidak perlu ada biaya untuk berkunjung ke tempat tersebut. Pengunjung tersebut membandingkan dengan destinasi wisata di sekitar Kepulauan Derawan yang tidak menetapkan tarif masuk untuk mengunjungi pulau, namun hanya membayar untuk jasa penginapan, transportasi, pemandu wisata, dan sewa peralatan selam.

Selanjutnya, perhitungan nilai total kesediaan membayar dengan menggunakan asumsi jumlah kunjungan wisatawan ke Berau tahun 2015 sebanyak 99 ribu wisatawan, maka diperoleh nilai total kesediaan membayar sebesar Rp. 1.423.914.894/tahun. Nilai tersebut merupakan potensi nilai ekonomi yang dimiliki dari pengembangan ekowisata mangrove dengan menggunakan data jumlah kunjungan wisatawan yang telah ada. Pada tahap operasional, nilai ini dapat saja menjadi lebih rendah atau lebih tinggi tergantung jumlah kunjungan wisatawan ke lokasi ekowisata mangrove di Tanjung Batu bila lokasi ini dijadikan sebuah destinasi ekowisata baru.

\section{KESIMPULAN}

Berdasarkan skoring dan pembobotan untuk menilai ODTWA, persepsi wisatawan dan masyarakat serta potensi nilai ekonomi yang dimiliki maka pengembangan ekowisata mangrove di Tanjung Batu prospektif untuk dilakukan ke depannya. Kawasan hutan mangrove di sekitar ex wisma atlet memiliki peluang untuk dikembangkan dengan peningkatan fasilitas atau infrastuktur pendukung. Pengembangan ekowisata mangrove ini dapat diselaraskan dengan konsep pembangunan 
Pusat Infromasi Mangrove (PIM) Berau yang pernah diinisiasi.

\section{UCAPAN TERIMAKASIH}

Penulis mengucapkan terimakasih dan penghargaan yang setinggi-tingginya kepada pihakpihak yang telah membantu dalam mengumpulkan data dalam penelitian ini, terutama kepada teknisi litkayasa Balai Penelitian dan Pengembangan Teknologi Konservasi Sumber Daya Alam (Balitek KSDA) Samboja: Deny Adi Putra dan Mukhaidil. Penulis juga mengucapkan terimakasih kepada rekan peneliti Dr. Kade Sidiyasa (Alm) untuk koreksi dan bantuan identifikasi lanjutan beberapa jenis mangrove yang telah dilakukan.

\section{DAFTAR PUSTAKA}

Anonim. 2003. Pedoman Analisis Daerah Operasi Obyek dan Daya Tarik Wisata Alam (ADOODTWA). Direktorat Jenderal Perlindungan Hutan dan Konservasi Alam. Departemen Kehutanan. Bogor.

Anonim. 2016. Turis Berburu Wisata di Berau. http://www.beraukab.go.id/berita/read/861/turi s-berburu-wisata-di-berau/. Diakses: 2 Agustus 2016.

Beljai, M., Muntasib, E.K.S.H., dan Sulistyantara, B., 2014. Konsep Penataan Lanskap untuk Wisata Alam di Kawasan Taman Wisata Alam Sorong. Jurnal Manusia dan Lingkungan 21(3):356-365.

Chua, V.L., Phillipps, Q., Lim, H.C., Taylor, S.S., Gawin, D.F., Rahman, M.A., Moyle, R.G., dan Sheldon, F.H., 2015. Phylogeography of Three Endemic Birds of Maratua Island, a Potential Archive of Bornean Biogeography. Raffles Bulletin of Zoology, 63:259-269.

Hasiani, F., Mulyani, E., dan Yuniarti, E., 2013. Analisis kesediaan membayar WTP (Willingness to Pay) dalam Upaya Pengelolaan Obyek Wisata Taman Alun Kapuas Pontianak, Kalimantan Barat. Jurnal Mahasiswa Teknik Lingkungan, 1(1):1-10.

Khoiri, F., Utomo, B., dan Lesmana, I., 2014. Analisis Kelayakan Pengembangan Ekowisata Mangrove di Pantai Muara Indah Kecamatan Pantai Labu Kabupaten Deli Serdang. Jurnal Aquacoastmarine, 2(1):48-55.

Kusaeri, Putro, S.P., dan Wasiq, J., 2015. Potensi Sumberdaya Alam Hayati Kawasan Mangrove Pasar Banggi Kabupaten Rembang Sebagai Objek Ekowisata. Biosaintifika, 2(5):120-127.

Laapo, A., Fahrudin, A., Bengen, D.G., dan Damar, A., 2010. Kajian Karakteristik dan Kesesuaian
Kawasan Mangrove Untuk Kegiatan Ekowisata Mangrove di Gugus Pulau Togean, Taman Nasional Kepulauan Togean. Forum Pascasarjana, 33(4):251-261.

Mellawati, J., Fepriadi, Yarianto, dan Laddade, T., 2010. Identifikasi Keanekaragaman Flora dan Fauna Berau Kalimantan Timur pada Kegiatan Pra Survei Tapak PLTN. Jurnal Pengembangan Energi Nuklir, 12(2):66-74.

Muhammad, F., Basuni, S., Munandar, A., dan Purnomo, H., 2010. Kajian Daya Dukung Ekowisata Hutan Mangrove Blanakan, Subang, Jawa Barat. Bioma, 14(2):64-72.

Mukhlisi dan Sidiyasa, K., 2014. Struktur Vegetasi dan Komposisi Jenis pada Hutan Mangrove di Pusat Informasi Mangrove (PIM) Berau, Kalimantan Timur. Indonesian Forest Rehabilitation Journal, 2(1) 25-37.

Mukhlisi, 2013. Inventarisasi Jenis-Jenis Burung di Hutan Mangrove Tanjung Batu, Kabupaten Berau, Provinsi Kalimantan Timur. Prosiding Seminar Nasional Pendidikan Sains. Universitas Negeri Sebelas Maret, Surakarta. 9 November 2013.

Mulyadi, E., dan Fitriani, N., 2010. Konservasi Hutan Mangrove Sebagai Ekowisata. Jurnal Ilmiah Teknik Lingkungan, 2(1):11-18.

Putra, A.C., Anggoro, S., dan Kismartini, 2015. Strategi Pengembangan Ekowisata Melalui Kajian Ekosistem Mangrove di Pulau Pramuka, Kepulauan Seribu. Jurnal Saintek Perikanan, 10(2):91-97.

Razak, A., dan Suprihardjo, 2013. Pengembangan Kawasan Pariwisata Terpadu di Kepulauan Seribu. Jurnal Teknik Pomits, 2(1):14-19.

Salim, H.L., dan Purbani, D., 2015. Pengembangan Pariwisata Bahari Berbasis Masyarakat di Pulau Kaledupa, Kabupaten Wakatobi, Provinsi Sulawesi Tenggara. Jurnal Manusia dan Lingkungan, 22(3):380-387.

Sudiarta, M., 2009. Ekowisata Hutan Mangrove: Wahana Pelestarian Alam dan Pendidikan Lingkungan. Analisis Pariwisata, 9(1):81-86.

Wiryawan, B., 2008. Linking Integrated Coastal Management and Marine Protected Area Development in Berau Islands, East Kalimantan, Indonesia. Buletin PSP, 7(3):325332.

Yuniarsih, A., Marsono, D., Pudyatmoko, S., dan Sadono, R., 2014. Pemodelan Sistem Pengusahaan Wisata Alam di Taman Nasional Gunung Ciremai, Jawa Barat. Jurnal Manusia dan Lingkungan, 21(2):220-231. 